\title{
Effect of nursing methods and faeces consumption on the development of the bacteroides, lactobacillus and coliform flora in the caecum of the newborn rabbits
}

\author{
Melinda KovÁcS*, Zsolt SzEndRŐ, Gábor MiLISITS, Brigitta BóTA, \\ Edit BÍRÓ-NÉMETH, István RADNAI, Roland PósA, András BÓNAI, \\ Ferenc KOVÁCS, Péter HORN
}

University of Kaposvár, Faculty of Animal Science, 7400 Kaposvár, Guba S. u. 40, Hungary

(Received 21 February 2005; accepted 10 January 2006)

\begin{abstract}
The effect of nursing method and ingestion of maternal faeces on the development of the bacteroides, lactobacillus and coliform flora of the caecum in the first 10 days of life were examined in freely nursed pups having access to maternal faeces (Group FF), pups nursed once a day and having access (Group CF), or having no access (Group CN) to maternal faeces. Colonisation of the caecum by Bacteroides commenced already on day 3 after birth. On day 2 the bacteroides counts were below 100, while on day 4 they were already between 100 and 10000 . In Group CN, the Bacteroides counts were lower (by 14 to $40 \%$ ) throughout the 10-day period studied than in the groups having access to maternal faeces. Differences between groups were significant only on days 4 and 6. The average number of maternal faecal pellets left behind the doe in Group CN was 3-4 (between 0.5 and 6.4 per doe). In Groups FF and CF the pellets became smaller, crumbled and finally disappeared from the nest box, they were consumed by the pups and could be found in their gastric content. The lactobacillus counts decreased in all three groups with age, from 6.0 to $3.5 \log 10 \mathrm{CFU} \cdot \mathrm{g}^{-1}$ (FF), 4.6 to $2.8 \log 10 \mathrm{CFU} \cdot \mathrm{g}^{-1}$ (CF) and 5.1 to $3.1 \log 10 \mathrm{CFU} \cdot \mathrm{g}^{-1}(\mathrm{CN})$, respectively. The coliform counts were higher in the first 4 days in FF $\left(5.6 \log 10 \mathrm{CFU} \cdot \mathrm{g}^{-1}\right)$ than in $\mathrm{CF}\left(<2 \log 10 \mathrm{CFU} \cdot \mathrm{g}^{-1}\right)$ and $\mathrm{CN}$ (2-3.6 $\left.\log 10 \mathrm{CFU} \cdot \mathrm{g}^{-1}\right)$ animals. Bacteroides could be cultured from the surface of the vulvar labia (max. 1000 colony count) and the vagina (max. 190 colony count), so young rabbits could become "infected" by them already in the doe's vagina. Thus prevention of ingestion of maternal faeces only slightly influenced the development of the bacteroides flora, the faeces left behind by the doe did not play an exclusive role in their colonisation.
\end{abstract}

newborn rabbit / caecal microflora / bacteroides / controlled and free nursing

\section{INTRODUCTION}

The caecal microflora and the fermentation processes taking place in the caecum play a key role in the digestion of rabbits. Imbalance of the intestinal microflora (dys- biosis) often plays a direct or indirect role in the development of digestive disturbances or diseases.

According to data of the literature [1-4], the concentration of the caecal bacterial

\footnotetext{
* Corresponding author: melinda@mail.atk.u-kaposvar.hu
} 
flora is $10^{9}-10^{11} \cdot \mathrm{g}^{-1}$, with the predominance of non-spore-forming, Gram-negative obligate anaerobes bacteroides, and the absence of the genera Lactobacillus and Straptococcus. Gouet and Fonty [5] found no or extremely reduced microflora during the first three days after birth, and observed

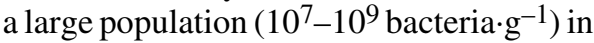
the caecum only after one week. Similar results were published by Smith [1] who did not isolate any bacteria in rabbits less than four days old.

According to observations [6] colonisation of bacteroides may be triggered by ingestion of the maternal faecal pellets, which are deposited by the doe towards the end of nursing. During the second week pups start eating these pellets which suggest that this can be beneficial regarding colonisation of the flora. However in our previous investigations $[7,8]$ we consistently found bacteroides in the caecum in a large amount $\left(10^{9}\right)$ already on the 7 th day after birth. This suggests that pups start eating faecal pellets early, a few days after birth, or, bacteria getting into the alimentary tract are from different origin.

In free nest-access conditions, domestic doe normally suckle their young only once a day, although she can visit the nest by several times (but without nursing). However, some doe may nurse two (or even three) times [9, 10]. Compared to a controlled nursing (once a day with nest closing), free nursing may result in visiting more frequently the nest and may result in more faecal pellets left in the nest which can presumably effect the rate of colonisation of the digestive tract by the flora.

The objective of the experiment was therefore to study the rate of development of some bacterial species of the caecal microflora in newborn rabbits after birth (between days 2-10) and the effect of nursing method (free or controlled nursing) and ingestion of maternal faeces on the colonisation of the caecum by bacteria.

\section{MATERIALS AND METHODS}

\subsection{Experimental animals}

Pannon White does and their progeny were used in the experiments. The does were kept in wirenet cages. At one end of the cage there was a nest box, with a creep-hole that could be closed. The nest box contained a nest tray. The rabbits were fed a commercial pelleted diet (crude protein: $17 \%$, crude

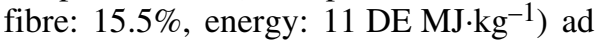
libitum. Drinking water was available from nipple drinkers ad libitum. The temperature of the room was $20-23{ }^{\circ} \mathrm{C}$ and the daily lighting period was $16 \mathrm{~h}$.

The one-day-old pups of average birth weight were distributed into litters of eight, and these litters (11 litters/group) were randomly divided into the following three groups: Group 'FF' (free nursing and free access to faeces): freely nursed pups having access to maternal faeces. In this group the nest box was continuously open; thus, the doe could enter the nest box and nurse freely according to the natural diurnal rhythm. Group ' $\mathrm{CF}$ ' (controlled nursing and free access to faeces): pups nursed once a day (in the morning) and having access to maternal faeces. In this group the nest box was closed and the does were allowed to enter the nest box and nurse only once a day, at 9:00 a.m. for 20-30 min. Group 'CN' (controlled nursing and no access to faeces): pups nursed once a day (in the morning) and having no access to maternal faeces. Also in this group, the does were allowed to enter the nest box and nurse only once a day, at 9:00 a.m. For the time of nursing the pups were removed from the nest and placed into a nest bowl bedded with clean wood shavings to ensure that no maternal faecal pellets remain in the nest and the pups have no opportunity to ingest them. The does were watched continuously and pups were placed back into the nest immediately after the doe finished nursing, then the maternal faecal pellets left in each nest bowl were collected and counted. 
The period during and shortly after dusk is related to an increase in nursing activity in the case of free nursing (Group FF). During this, the does usually leave some faecal pellets in the nest. However in this case it is impossible to prevent pups from consuming the faeces. So creation of Group CN was needed, where nursing was restricted to 20 $30 \mathrm{~min}$ in the morning, so collection and counting of the pellets became possible. By controlled nursing postponement between nursing and defecation may occur. Therefore another group $(\mathrm{CF})$ was needed where the similar nursing method would result presumably in similar amount of faecal pellets left in the nest, than in Group $\mathrm{CN}$.

\subsection{Experimental design}

Six young rabbits were examined by group on days 2, 4, 6, 8 and 10 after birth. The pups were euthanised (between 11:00 and 12:00 a.m.) by an overdose of carbon dioxide and bled. After opening the abdominal cavity and isolating the caecum, samples were taken from the caecal content with sterile precautions and subjected to microbiological analysis.

After kindling, swab samples were taken from the vagina of six does from each group, from the surface of the vulva, from the skin of the nipples and the surrounding fur, and then these samples were also subjected to microbiological analysis. The surface of the organs examined was swabbed with a sterile cotton swab dampened with $0.9 \% \mathrm{NaCl}$ (physiological saline) solution. The content of the swab was immediately smeared on Schaedler's agar and then put into anaerobic conditions (see below).

We had the permit necessary for performing the animal experiment (MÁB-10/ 2002).

\subsection{Microbiological examinations}

The microbiological examinations included the determination of the number of Bacteroides as the main component of the caecal microflora in rabbits [1, 2, 5], lactobacilli and coliforms as the flora which is introduced first after birth into the GI tract by suckling, from the vagina during birth or from the environment in many species $[11,12]$.

From one gram of caecal chyme serial dilutions (with $0.9 \% \mathrm{NaCl}$ ) were made immediately after sampling and used for determination of the bacteroides, lactobacillus and coliform counts. The different dilutions $\left(10^{6-7-8}\right.$ for bacteroides, $10^{2-3-4}$ for lactobacilli and $10^{3-4-5}$ for coliforms) were smeared onto the surface of the selective culture media.

The obligate anaerobe Bacteroides organisms were cultured on Schaedler's agar (Sharlan Chemie, Barcelona, Spain), the selectivity of which was increased by the addition of esculin (Merck, Darmstadt, Germany), neomycin (Merck, Darmstadt, Germany) and Fe-ammonium citrate (Sharlan Chemie, Barcelona, Spain). The gamma sterile Petri dishes (Biolab, Budapest) were placed into Anaerocult culture dishes (Merck, Darmstadt, Germany), in which the anaerobic conditions were ensured with the help of an "Anaerocult A" (Merck, Darmstadt, Germany) gasifying bag. Subsequently the samples were incubated in an LP 104 type thermostat (LMIM, Esztergom, Hungary) at $37^{\circ} \mathrm{C}$ for $96 \mathrm{~h}$. Lactobacilli were cultured on MRS agar (Sharlan Chemie, Barcelona, Spain). The cultures were incubated in an LP 116 type facultative anaerobic thermostat (LMIM, Esztergom, Hungary) at $37^{\circ} \mathrm{C}$ for 48 h. Coliforms (incl. E. coli) were cultured on a Chromocult differentiation medium (Merck, Darmstadt, Germany). The samples were incubated in thermostat at $37^{\circ} \mathrm{C}$, under aerobic conditions, for $24 \mathrm{~h}$. After the incubation time had elapsed, the colonies were counted with a Titriplaque colony counter(LMIM, Esztergom, Hungary). The colony counts were expressed in $\log 10$ colony forming units (CFU) related to $1 \mathrm{~g}$ of sample. 
Table I. Number of bacteroides, lactobacilli and coliforms expressed in $\log 10$ germ count $\cdot \mathrm{g}^{-1}$ chyme (average, minimum and maximum values).

\begin{tabular}{|c|c|c|c|c|c|}
\hline \multirow[t]{2}{*}{ Group } & \multicolumn{5}{|c|}{ Age (days) } \\
\hline & 2 & 4 & 6 & 8 & 10 \\
\hline \multicolumn{6}{|c|}{ bacteroides } \\
\hline $\begin{array}{l}\mathrm{FF} \\
(n=6)\end{array}$ & $<2$ & $\begin{array}{c}4.7^{\mathrm{aA}} \\
(<2-6.0)\end{array}$ & $\begin{array}{c}7.2^{\mathrm{aB}} \\
(6.5-7.7)\end{array}$ & $\begin{array}{c}8.2^{\mathrm{C}} \\
(7.8-8.5)\end{array}$ & $\begin{array}{c}8.5^{\mathrm{C}} \\
(8.1-9.0)\end{array}$ \\
\hline $\begin{array}{l}\mathrm{CF} \\
(n=6)\end{array}$ & $<2$ & $\begin{array}{c}4.2^{\mathrm{aA}} \\
(3-5.2)\end{array}$ & $\begin{array}{c}6.0^{\mathrm{abB}} \\
(4.8-7.1)\end{array}$ & $\begin{array}{c}7.8^{\mathrm{C}} \\
(6.4-9.2)\end{array}$ & $\begin{array}{c}8.6^{\mathrm{C}} \\
(8.3-8.9)\end{array}$ \\
\hline $\begin{array}{l}\mathrm{CN} \\
(n=6)\end{array}$ & $<2$ & $\begin{array}{c}2.4^{\mathrm{bA}} \\
(<2-2.6)\end{array}$ & $\begin{array}{c}4.3^{\mathrm{bB}} \\
(4.0-5.0)\end{array}$ & $\begin{array}{c}6.3^{\mathrm{C}} \\
(2.0-8.0)\end{array}$ & $\begin{array}{c}7.3^{\mathrm{C}} \\
(6.0-8.5)\end{array}$ \\
\hline \multicolumn{6}{|c|}{ lactobacilli } \\
\hline $\begin{array}{l}\mathrm{FF} \\
(n=6)\end{array}$ & $\begin{array}{c}6.0^{\mathrm{A}} \\
(4.2-7.7)\end{array}$ & $\begin{array}{c}4.0^{\mathrm{aB}} \\
(3.3-4.3)\end{array}$ & $\begin{array}{c}4.8^{\mathrm{AB}} \\
(3.2-6.2)\end{array}$ & $\begin{array}{c}4.1^{\mathrm{B}} \\
(3.4-5.5)\end{array}$ & $\begin{array}{c}3.5^{\mathrm{B}} \\
(<2-4.7)\end{array}$ \\
\hline $\begin{array}{l}\mathrm{CF} \\
(n=6)\end{array}$ & $\begin{array}{c}4.6^{\mathrm{A}} \\
(3.6-5.7)\end{array}$ & $\begin{array}{l}3.9^{\mathrm{abAB}} \\
(2.7-5.3)\end{array}$ & $\begin{array}{c}3.1^{\mathrm{AB}} \\
(2.0-3.7)\end{array}$ & $\begin{array}{c}3.7^{\mathrm{AB}} \\
(2.3-6.1)\end{array}$ & $\begin{array}{c}2.8^{\mathrm{B}} \\
(<2-4.3)\end{array}$ \\
\hline $\begin{array}{l}\mathrm{CN} \\
(n=6)\end{array}$ & $\begin{array}{c}5.1^{\mathrm{A}} \\
(4.5-5.4)\end{array}$ & $\begin{array}{c}3.6^{\mathrm{bB}} \\
(3.1-4.1)\end{array}$ & $\begin{array}{c}2.7^{\mathrm{B}} \\
(2.5-2.9)\end{array}$ & $\begin{array}{c}3.1^{\mathrm{B}} \\
(2.0-4.3)\end{array}$ & $\begin{array}{c}3.1^{\mathrm{B}} \\
(<2-4.1)\end{array}$ \\
\hline \multicolumn{6}{|c|}{ coliforms } \\
\hline $\begin{array}{l}\mathrm{FF} \\
(n=6)\end{array}$ & $\begin{array}{c}5.6^{\mathrm{ABC}} \\
(3.5-7.7)\end{array}$ & $\begin{array}{c}5.6^{\mathrm{ABC}} \\
(4.8-6.0)\end{array}$ & $\begin{array}{c}4.1^{\mathrm{aA}} \\
(3.4-6.8)\end{array}$ & $\begin{array}{c}6.4^{\mathrm{B}} \\
(5.2-7.0)\end{array}$ & $\begin{array}{c}4.3^{\mathrm{AC}} \\
(3.0-6.4)\end{array}$ \\
\hline $\begin{array}{l}\text { CF } \\
(n=6)\end{array}$ & $<2$ & $<2$ & $\begin{array}{c}4.0^{\mathrm{a}} \\
(<2-5.9)\end{array}$ & $\begin{array}{c}4.2 \\
(3.1-6.1)\end{array}$ & $\begin{array}{c}3.8 \\
(<2-5.3)\end{array}$ \\
\hline $\begin{array}{l}\mathrm{CN} \\
(n=6)\end{array}$ & $<2$ & $\begin{array}{c}3.6^{\mathrm{A}} \\
(<2-6.7)\end{array}$ & $\begin{array}{c}6.7^{\mathrm{bB}} \\
(6.5-7.0)\end{array}$ & $\begin{array}{c}6.4^{\mathrm{BC}} \\
(5.2-7.0)\end{array}$ & $\begin{array}{l}5.4^{\mathrm{ABC}} \\
(<2-7.7)\end{array}$ \\
\hline
\end{tabular}

Significant $(P<0.05)$ difference between ${ }^{\mathrm{a}, \mathrm{b}}$ groups and $\mathrm{A}, \mathrm{B}$ dates.

FF: free nursing and free access to faeces, CF: controlled nursing and free access to faeces, CN: controlled nursing and no access to faeces.

Swab samples taken from the does were cultured only for bacteroides (see above) and the colonies formed were counted.

\subsection{Statistical analysis}

Statistical analysis of the data obtained was carried out by the SPSS for Windows statistical software package using the version 7.5 [13]. Effect of treatment, age and their interaction was analyzed by the following general linear model:

$$
y_{\mathrm{ijk}}=\mu+T_{\mathrm{i}}+A_{\mathrm{j}}+T A_{\mathrm{ij}}+e_{\mathrm{ijk}}
$$

where $\mu=$ mean, $T_{\mathrm{i}}=$ effect of treatment, $A_{\mathrm{j}}=$ effect of age, $T A_{\mathrm{ij}}=$ interaction of treatment and age, $e_{\mathrm{ijk}}=$ random error.

The significance of between groups differences was tested by the LSD post hoc test.

\section{RESULTS}

Results of the microbiological examination of the caecal content indicate that colonisation of the caecum by Bacteroides microorganisms commences already on day 3 after birth (Tab. I). The most expressed 
increase was observed between days 4-8, when significant differences were found between sapling dates. In Group $\mathrm{CN}$, the bacteroides counts were substantially lower throughout the 10-day period studied than in the groups having access to maternal faeces. On day 6 the bacteroides counts were slightly lower in Group CF than in Group FF. This not significant difference was still present on day 8 but then disappeared by day 10 after birth.

In Group $\mathrm{CN}$, the faecal pellets left behind by the does in the nest bowl were collected and counted. On the second day, maternal faeces was found in only 2 out of the 11 nest bowls examined. However, from the subsequent day all the nest bowls contained maternal faecal pellets, with the exception of only one or two cases. The average number of maternal faecal pellets was 3; however, this was subject to great variation by doe: some does regularly left behind 0-2 (in average 0.5 ) while others 512 (in average 6.4) faecal pellets in the nest bowl.

In Groups FF and CF all pups were taken out of the nest for a few minutes and the fate of the faecal pellets was controlled in every 2-3 h. We found that the pellets became smaller, crumbled and finally disappeared from the nest box, possibly because the young pups had ingested them. The examination of the stomach supported that pups have effectively eaten faeces, as it could be found in the gastric content.

In this experiment the lactobacillus counts decreased in all three groups with age. The number of lactobacilli was slightly (but not significantly) higher in the freely nursed group (Group FF) throughout (Tab. I).

The coliform counts were higher in the first 4 days in Group FF than in Group CF and $\mathrm{CN}$ (Tab. I). In Group $\mathrm{CN}$ a marked increase in the coliform counts could be found on day 6 and on day 10 the coliform counts were still higher in this group than in the other two groups, however differences were not significant. In this group a high negative correlation was found between coliforms and lactobacilli. In Group FF a transient germ count increase was observed on day 8 . We have never found significant interaction between age and treatment.

The results of the microbiological examination of samples taken from the does indicated that Bacteroides organisms were present in the highest number on the surface of the vulvar labia and in the vagina (1901000 colonies), a few bacteria (2-9 colonies) could also be cultured from the nipples and the fur.

\section{DISCUSSION}

The results of the present experiment demonstrate that the type of nursing (oncea-day or free nursing) and access to maternal faeces exert an influence on the development and composition of the caecal microflora in the first ten days of life.

In Groups FF and CF the young pups of a few days of age began to ingest the faecal pellets left behind by their doe, and this accounted for early and rapid colonisation of the caecum by bacteroides. This assumption seemed to be reinforced by the observation of the gastric content of the pups and finding solid parts of faeces in it. The low number of the pellets left sometimes behind the $\mathrm{CN}$ does may indicate that in case of controlled nursing there is a postponement between nursing and defecation.

The slightly slower bacteroides and coliform colonisation observed in Group CF compared to FF may have been due to the fact that at the given nursing time the does excreted fewer faecal pellets than does having free access to the nest box. Recent results showed that after parturition 20$30 \%$ of does go into the next box more a day and may patiently wait as long as ten minutes to nurse their young $[9,14]$. So they spend more time in the nest and may leave more faecal pellets behind.

In $\mathrm{CN}$ pups bacteria could get into the digestive tract from the does' genital organs, fur or nipples or from the environment (i.e. 
from the nest) in numbers sufficient to trigger colonisation.

Free nursing resulted in higher lactobacillus counts throughout, presumably because the does had more time for nursing and they could nurse their pups twice or more times a day. Presumably the initially higher coliform count found in Group FF was also due to free nursing and more faecal pellets left behind the doe. Previous studies [7, 15, 16] showed that twice-a-day nursing resulted in higher coliform counts in addition to the higher lactobacillus counts. The higher coliform counts found in Group CN between days 6 and 10 were probably attributable to the slower development of the bacteroides and lactobacillus flora.

In conclusion it can be established that colonisation of the caecum by bacteroides occurred at a faster rate in freely nursed pups having unlimited access to the doe's faecal pellets. The use of once-a-day nursing (in the morning) did not result in significant differences. Prevention of the ingestion of maternal faeces only slightly influenced the development of the bacteroides flora. These findings prove that the faeces left behind by the doe does not play an exclusive role in colonisation of the caecum by Bacteroides.

\section{ACKNOWLEDGEMENT}

The research was supported by the OTKA foundation (project No.: T046999 and TS 044743).

\section{REFERENCES}

[1] Smith HW. The development of the flora of the alimentary tract in young animals. J Pathol Bacteriol 1965, 90: 495-513.

[2] Smith HW. Observations on the flora of the alimentary tract in young animals and factors effecting its composition. J Pathol Bacteriol 1965, 89: 95-122.

[3] Bornside GH, Cohn IH. The normal microbial flora. Comparative bacterial flora of animals and man. Amer J Dig Dis 1965, 10: 844-852.
[4] Gouet P, Fonty G. Évolution de la microflore digestive du lapin holoxénique de la naissance au sevrage. Ann Biol Anim Bioch Biophys 1973, 13: 733-734.

[5] Gouet P, Fonty G. Changes in the digestive microflora of holoxenic rabbits from birth until adulthood. Ann Biol Anim Bioch Biophys 1979, 19: 553-566.

[6] Hudson R, Schaal B, Bilko Á, Altbäcker V. Just three minutes a day: The behaviour of young rabbits viewed in the context of limited maternal care. 6th World Rabbit Congress, Toulouse, Vol 2, 1996, p 395-403.

[7] Kovács M, Gyarmati T, Szendrő Zs, Bencsné KZ, Donkó T, Tornyos G, Lukács H, Bóta B. Effect of double nursing and early weaning on development of caecal microflora of the rabbit (in Hungarian). Magy Áo Lapja 2002, 124: 742-748.

[8] Kovács M, Szendrő Zs, Csutorás I, Bóta B, Fébel H, Kósa E, Bencs-Köllő Z, Szakács Á, Horn P. Some digestive-physiological parameters of early-weaned rabbits fed nonmedicated diets. 8th World Rabbit Congress, Puebla City, 2004, p 1097-1102.

[9] Hoy ST, Selzer D. Frequency and time of nursing in wild and domestic rabbits housed outdoors in free range. World Rabbit Sci 2002, 10: 77-83.

[10] Selzer D, Lange K, Hoy S. Frequency of nursing in domestic rabbits under different housing conditions. Appl Anim Behav Sci 2004, 87: $317-324$

[11] Ewing WN, Cole DJA. The Living Gut. Context Press, Dungannon, Ireland, 1994.

[12] Fanaro S, Chierici R, Guerrini P, Vigi V. Intestinal microflora in early infancy: composition and development. Acta Pediatr 2003 (Suppl), 441: 48-55.

[13] SPSS Inc 1996. SPSS for Windows, Version 7.5, Chicago, IL

[14] Matics Zs, Szendrő Zs, Theau-Clément M, Bíró NE, Radnai I, Gyovai M, Orova Z, Eiben Cs. Modification of the nursing system as a biostimulation method. 8th World Rabbit Congress, Puebla City, 2004, 298-302.

[15] Zomborszky-Kovács M, Gyarmati T, Párizs T, Szendrő Zs, Kametler L, Tóth Á. Some physiological properties of the digestive tract in traditionally reared and exclusively milkfed young rabbits. World Rabbit Sci 2000, 8: 499-506.

[16] Padilha MTS, Licois D, Gidenne T, Carre B, Condert P, Lebas F. Caecal microflora and fermentation pattern in exclusively milk-fed young rabbits. 6th World Rabbit Congress, Toulouse, Vol 1, 1996, p 247-251. 